\title{
Minimally invasive lateral approach for adult degenerative scoliosis: lessons learned
}

\author{
Armen R. Deukmedjian, M.D., Amir Ahmadian, M.D., Konrad BaCh, M.D., \\ Alexandros Zouzias, M.D., and Juan S. Uribe, M.D. \\ Department of Neurosurgery and Brain Repair, University of South Florida, Tampa, Florida
}

\begin{abstract}
Object. Lateral minimally invasive thoracolumbar instrumentation techniques are playing an increasing role in the treatment of adult degenerative scoliosis. However, there is a paucity of data in determining the ideal candidate for a lateral versus a traditional approach, and versus a hybrid construct. The objective of this study is to present a method for utilizing the lateral minimally invasive surgery (MIS) approach for adult spinal deformity, provide clinical outcomes to validate our experience, and determine the limitations of lateral MIS for adult degenerative scoliosis correction.

Methods. Radiographic and clinical data were collected for patients who underwent surgical correction of adult degenerative scoliosis between 2007 and 2012. Patients were retrospectively classified by degree of deformity based on coronal Cobb angle, central sacral vertical line (CSVL), pelvic incidence, lumbar lordosis (LL), sagittal vertical axis (SVA), pelvic tilt (PT), presence of comorbidities, bone quality, and curve flexibility. Patients were placed into 1 of 3 groups according to the severity of deformity: "green" (mild), "yellow" (moderate), and "red" (severe). Clinical outcomes were determined by a visual analog scale (VAS) and the Oswestry Disability Index (ODI).

Results. Of 256 patients with adult degenerative scoliosis, 174 underwent a variant of the lateral approach. Of these 174 patients, 27 fit the strict inclusion/exclusion criteria $(n=9$ in each of the 3 groups). Surgery in 17 patients was dictated by their category, and 10 were treated with surgery outside of their classification. The average age was 61 years old and the mean follow-up duration was 17 months. The green and yellow groups experienced a reduction in coronal Cobb angle $\left(12^{\circ}\right.$ and $11^{\circ}$, respectively), and slight changes in CSVL, SVA, and PT, and LL. In the green group, the VAS and ODI improved by 35 and 17 points, respectively, while in the yellow group they improved by 36 and 33 points, respectively. The red subgroup showed a $22^{\circ}$ decrease in coronal Cobb angle, $15^{\circ}$ increase in LL, and slight changes in PT and SVA. Three patients placed in the yellow subgroup had "green" surgery, and experienced a coronal Cobb angle and LL decrease by $17^{\circ}$ and $10^{\circ}$, respectively, and an SVA and PT increase by $1.3 \mathrm{~cm}$ and $5^{\circ}$, respectively. Seven patients placed in the red group who underwent "yellow" or "green" surgery had a reduction in coronal Cobb angle of $16^{\circ}$, CSVL of $0.1 \mathrm{~cm}$, SVA of $2.8 \mathrm{~cm}$, PT of $4^{\circ}$, VAS of 28 points, and ODI of 12 points; lumbar lordosis increased by $15^{\circ}$. Perioperative complications included 1 wound infection, transient postoperative thigh numbness in 2 cases, and transient groin pain in 1 patient.

Conclusions. Careful patient selection is important for the application of lateral minimally invasive techniques for adult degenerative scoliosis. Isolated lateral interbody fusion with or without instrumentation is suitable for patients with preserved spinopelvic harmony. Moderate sagittal deformity (compensated with pelvic retroversion) may be addressed with advanced derivatives of the lateral approach, such as releasing the anterior longitudinal ligament. For patients with severe deformity, the lateral approach may be used for anterior column support and to augment arthrodesis.
\end{abstract}

(http://thejns.org/doi/abs/10.3171/2013.5.FOCUS13173)

KEY WoRDS $\quad$ adult spinal deformity $\quad$ adult degenerative scoliosis
$\begin{aligned} & \text { lateral retroperitoneal approach } \\ & \text { direct lateral interbody fusion }\end{aligned} \quad \bullet \quad$ extreme lateral interbody fusion
minimally invasive surgery $\quad$ complications

$\mathrm{M}$ INIMALLY invasive spine surgery was developed to address approach-related morbidity associated with traditional open spine surgery. Over the last decade the application of MIS techniques for the

\footnotetext{
Abbreviations used in this paper: ALIF = anterior lumbar interbody fusion; $\mathrm{ALL}=$ anterior longitudinal ligament; $\mathrm{CSVL}=$ central sacral vertical line; $\mathrm{LL}=$ lumbar lordosis; $\mathrm{MIS}=$ minimally invasive surgery; ODI = Oswestry Disability Index; PI = pelvic incidence; PT $=$ pelvic tilt; SVA = sagittal vertical axis; VAS = visual analog scale.
}

spine has continued to evolve and expand..$^{4,5,9,12,16,22,37}$ As the field continues to advance, MIS techniques have been implemented in the treatment of more complex patient pathologies, including adult degenerative scoliosis, the prevalence of which has increased due to increasing life expectancy. In recent publications, Wang et al. described techniques for mini-open pedicle subtraction osteotomy as well as percutaneous iliac screw placement, which may become invaluable tools in the future treatment of adult degenerative scoliosis. ${ }^{37-39}$ The traditional surgical cor- 


\section{A. R. Deukmedjian et al.}

rection of adult degenerative scoliosis incorporates extensive open spinal mobilization and then reconstruction with long multilevel implants, and may confer significant morbidity. Less invasive techniques have the potential for muscle mass preservation and decreased physiological stress, blood loss, narcotic use, and length of hospital stay. However, MIS techniques have their own set of challenges and complications. Difficulties related to MIS correction of adult degenerative scoliosis are particularly associated with its steep learning curve and technical limitations, and require a full understanding of the fundamentals of spinal deformity correction as well as the technical limitations of MIS instrumentation.

Lateral MIS instrumentation techniques have played an increasing role in the treatment of adult degenerative scoliosis, which is characterized by spinal curvature greater than $10^{\circ}$ with associated derangement of spinopelvic alignment. ${ }^{1,6,28}$ It can be used as a unique standalone treatment, or as a source of anterior column support to provide fusion and possible deformity correction. Progressive deformity that develops after skeletal maturity is related to asymmetrical degeneration of intervertebral discs, compression fractures, and/or osteoporosis. Classification of adult degenerative scoliosis severity, both radiographically and clinically, is critical to selecting the appropriate treatment paradigm. ${ }^{30}$ The timing of surgical intervention, the surgical approach, and the length of constructs for operative correction have been controversial.

Patient selection is an important factor when electing to use an MIS approach, because not all patients are candidates for this approach due to the extent of deformity. The MIS decision-making process includes a thorough analysis of clinical and radiographic parameters to establish benchmark surgical objectives for neural decompression, restoration, and maintenance of spinal balance in a similar fashion to traditional open techniques. Each lateral MIS surgical technique or variation has its unique impact on deformity correction and can be used alone or combined with others. There is a paucity of data in determining the ideal candidate for a lateral MIS versus a traditional open approach, and versus hybrid constructs. In this paper we present a follow-up study of our singlecenter experience with the lateral MIS technique for adult degenerative scoliosis, with a refined understanding of the importance of sagittal balance correction. ${ }^{9}$

The purpose of this project is to provide a roadmap to guide the surgical treatment of adult degenerative scoliosis using minimally invasive lateral anterior/posterior interbody arthrodesis, anterior column release, posterior decompression, and posterior percutaneous instrumentation. We also discuss the use of hybrid constructs incorporating traditional posterior osteotomies. Our objectives of this project are to: 1) present and validate a surgical method for utilization of the lateral MIS approach for adult degenerative scoliosis; 2) analyze construct-specific clinical outcomes and complications; and 3) determine the limitation of lateral MIS for adult degenerative scoliosis. We discuss specific strategies we have developed and refined for realizing these objectives using our institutional standardized MIS adult degenerative scoliosis classification.

\section{Methods}

\section{Data Collection}

In an effort to deliver reproducible outcomes, we performed a retrospective review of a prospectively acquired database of patients who underwent lateral MIS correction of adult degenerative scoliosis at the University of South Florida between 2007 and 2012. Initial clinical evaluation was performed by the senior author (J.S.U.) and included a detailed history and physical examination to determine signs and symptoms, comorbidities, bone quality, and age. Spinopelvic parameters as well as clinical outcomes were measured and recorded both preoperatively and postoperatively. Patients were classified by degree of deformity based on coronal Cobb angle, PI, LL, SVA, PT, presence of comorbidities, and curve flexibility. The presence of a fractional curve at L5/S1 was also evaluated for treatment options.

\section{Outcome Measures and Follow-Up}

Outcome measures included integrity of the construct, degree of correction, complications, fusion rates, and VAS and ODI patient questionnaires. Outcome questionnaires were obtained at each interval follow-up period. Clinical follow-up evaluation was scheduled postoperatively at 4 weeks, 3 months, 6 months, 1 year, and 2 years from the date of surgery. Inclusion criteria of the study were: 1) presence of spinal deformity (characterized by coronal Cobb angle $>10^{\circ}$ ); 2) having undergone lateral MIS or hybrid approach for arthrodesis and correction; 3) minimum of 12-month clinical follow-up with outcome measures; 4) adequate preoperative and postoperative 36-inch standing radiographs; and 5) 12-month CT scan. Exclusion criteria were: 1) severe medical comorbidities that would render a patient unable to tolerate adult degenerative scoliosis correction; 2) bone density less than -2.0 on preoperative dual-energy $\mathrm{x}$-ray absorptiometry; 3) adolescent idiopathic scoliosis; 4) concurrent presence of Parkinson disease; 5) retroperitoneal fibrosis; 6) vascular anomalies prohibiting lateral access; and 7) previous surgical procedures for adult degenerative scoliosis correction.

\section{Surgical Techniques}

Surgeries performed included both MIS and open techniques. Included in the MIS group were the lateral retroperitoneal transpsoas approach, presacral lumbar interbody fusion, mini-open ALIF, mini-open transforaminal lumbar interbody fusion, posterior percutaneous pedicle screw fixation, ALL release from the lateral position, and segmental thoracolumbar release facetectomies. Open techniques included laminectomy/foraminotomy, open pedicle screw fixation, Smith-Petersen/Ponte osteotomies, and pedicle subtraction osteotomies. Fusion was determined using postoperative CT at 12 months. Complications were analyzed and recorded. Clinical score averages were determined preoperatively and at the most recent follow-up evaluation. The paired t-test was used to compare means. Probability values were determined for each clinical outcome measure. 


\section{Surgical Subgroups}

After 5 years of experience and knowledge gained from mistakes made with the lateral approach, we propose a guide for surgical decision making using radiographic parameters (Fig. 1), with the understanding that much more is involved. Patients with adequate sagittal balance (SVA $<5 \mathrm{~cm}$ ) and spinopelvic harmony (PI-LL $<20^{\circ}$ and $\mathrm{PT}<25^{\circ}$ ) were placed into the green group (mild spinopelvic disharmony) and were considered suitable for a simple stand-alone construct or limited fusion at the apex of the curve with lateral MIS interbody fusion with or without posterior instrumentation. Patients with moderate spinopelvic disharmony (SVA 5-9 cm, PI-LL $20^{\circ}-30^{\circ}$, and/or PT $25^{\circ}-30^{\circ}$ ) were classified into the yellow group, requiring MIS interbody fusion with posterior instrumentation and the addition of ALL release or MIS facetectomy to obtain adequate correction. Finally, patients with severe spinopelvic malalignment (SVA > $10 \mathrm{~cm}$ with fixed curves, $\mathrm{PT}>30^{\circ}$, and/or PI-LL $>30^{\circ}$ ) were classified into the red group and likely to require traditional open posterior osteotomies with or without multilevel ALL release hybrid constructs to obtain adequate correction. At our institution, not all patients fall into these surgical categories, which will be discussed in the following section.

\section{Results}

Of 256 patients with adult degenerative scoliosis, defined as having a coronal Cobb angle greater than $10^{\circ}, 174$ underwent surgical intervention using a variant of the lateral approach. Of those 174 patients, 27 fit the inclusion/ exclusion criteria. Among these 27 patients, there were 11 males and 16 females, with an average age of 61 years and a mean follow-up duration of 17 months.

There were 9 patients in each group, but 10 patients ( 3 in the yellow group and 7 in the red group) underwent a less extensive surgery than we discuss in our categorization scheme ("undertreated" classification). There were no statistically significant differences in the ages or follow-up durations between the groups (Tables 1 and 2). All patients achieved adequate fusion, as determined using a 12-month postoperative $\mathrm{CT}$ scan read by a radiologist as well as a member of the surgical team. Perioperative complications included 1 patient with a deep wound infection requiring debridement and intravenous antibiotics (4\%), 2 patients (8\%) with transient postoperative anterior thigh numbness ipsilateral to the side of approach in the distribution of the lateral femoral cutaneous nerve (Zone 2 ), and 1 patient (4\%) with transient groin pain in the distribution of the ilioinguinal nerve (Zone 1). ${ }^{2}$ Tables 3 and 4 list changes in parameters for each subgroup from preoperatively to postoperatively.

\section{Green Group}

The green subgroup included 9 patients classified into the "green" category that underwent a "green" surgery. No patients in this subgroup received the incorrect surgery according to the classification scheme. The coronal Cobb angle decreased by $12^{\circ}(\mathrm{p}<0.001)$, CSVL increased by $0.2 \mathrm{~cm}(\mathrm{p}=0.717)$, SVA increased by $0.6 \mathrm{~cm}$ (p $=0.9)$, PT increased by $1^{\circ}(\mathrm{p}=0.52)$, and LL increased by $1^{\circ}(\mathrm{p}=0.67)$. The VAS and ODI scores decreased by 35 ( $\mathrm{p}$ $=0.004)$ and $17(\mathrm{p}=0.006)$ points, respectively.

\section{Yellow Group}

The yellow subgroup included 6 patients classified into the "yellow" category who underwent a "yellow" surgery. Coronal Cobb angle had a statistically significant decrease of $11^{\circ}(\mathrm{p}=0.001)$, CSVL decreased by $0.7 \mathrm{~cm}$, SVA decreased by $1.4 \mathrm{~cm}, \mathrm{PT}$ decreased by $1^{\circ}$, and LL increased by $7^{\circ}(p=0.02)$. The VAS and ODI scores both demonstrated statistically significant decreases of 36 ( $\mathrm{p}=$ $0.03)$ and $33(\mathrm{p}=0.002)$, respectively.

\section{Yellow Undertreated Group}

The yellow undertreated subgroup contained the 3 patients classified into the "yellow" category who un-

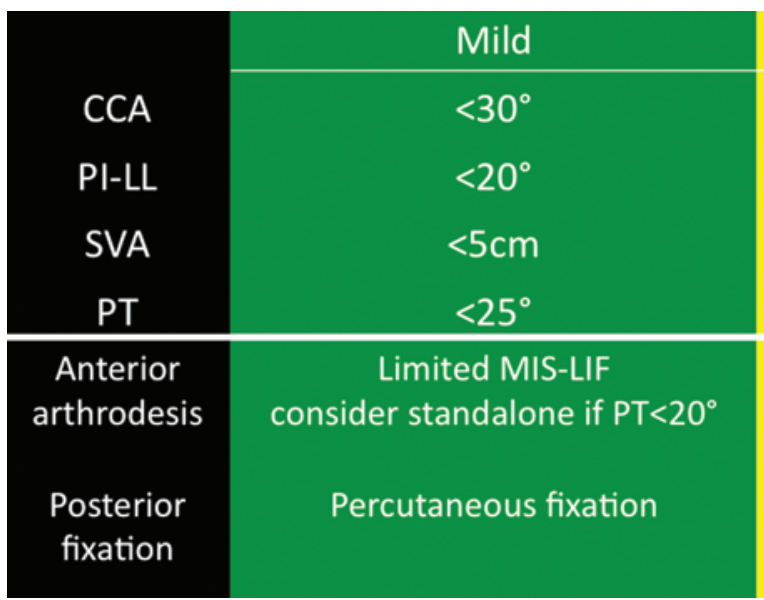

Moderate
$>30$
$20^{\circ}-30^{\circ}$
$5-9 \mathrm{~cm}$
$25-30^{\circ}$
MIS-LIF to neutral
vertebrae + ALLR
Percutaneous fixation \pm
facetectomy

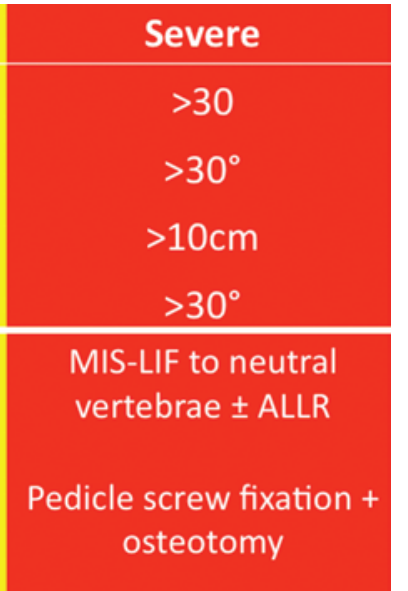

FIG. 1. Radiographic subgroups and related surgical intervention. Green: Represents radiographic parameters of patients with mild symptomatic deformity and spinopelvic compensation. Yellow: Represents radiographic parameters of patients with moderate symptomatic deformity and associated lack of sagittal balance with SVA between $5 \mathrm{~cm}$ and $9 \mathrm{~cm}$. Red: Represents radiographic parameters of patients with severe symptomatic deformity and associated lack of sagittal balance with SVA greater than $10 \mathrm{~cm}$ despite maximal PT. ALLR = ALL release; CCA = coronal Cobb angle; LIF = lateral interbody fusion. 
A. R. Deukmedjian et al.

TABLE 1: Cohort demographics

\begin{tabular}{lccc}
\hline \multicolumn{1}{c}{ Group } & No. of Patients $(\mathrm{M} / \mathrm{F})$ & Age Range (average) $^{*}$ & Average Follow-Up (mos) $^{*}$ \\
\hline green & $9(4 / 5)$ & $61-71(67)$ & 15.2 \\
yellow & $6(3 / 3)$ & $53-66(59)$ & 18 \\
yellow undertreated & $3(0 / 3)$ & $54-74(62)$ & 16 \\
red & $2(0 / 2)$ & $59-69(65)$ & 19 \\
red undertreated & $7(4 / 3)$ & $32-73(53)$ & 18 \\
\hline
\end{tabular}

* Age given in years.

derwent a "green" surgery, and showed no statistically significant different values preoperatively to postoperatively. Coronal Cobb angle, LL, VAS, and ODI decreased by $17^{\circ}, 10^{\circ}, 30$ points, and 17 points, respectively. The CSVL, SVA, and PT increased by $0.3 \mathrm{~cm}, 1.3 \mathrm{~cm}$, and $5^{\circ}$, respectively.

\section{Red Group}

The red subgroup contained the 2 patients classified into the "red" category who underwent a "red" surgery. The coronal Cobb angle, SVA, PT, VAS, and ODI decreased by $22^{\circ}, 0.1 \mathrm{~cm}, 1^{\circ}, 15$ points, and 10 points, respectively, while the CSVL and LL increased by $1.5 \mathrm{~cm}$ $(\mathrm{p}=0.009)$ and $15^{\circ}$, respectively.

\section{Red Undertreated Group}

The red undertreated subgroup contained 7 patients classified into the "red" category who underwent either a "yellow" or a "green" surgery. The coronal Cobb angle, CSVL, SVA, PT, VAS, and ODI decreased by $16^{\circ}(\mathrm{p}=$ $0.003), 0.1 \mathrm{~cm}, 2.8 \mathrm{~cm}, 4^{\circ}, 28$ points, and 12 points, respectively, while the LL increased by $15^{\circ}(\mathrm{p}=0.04)$.

\section{Illustrative Cases}

\section{Case 7 (Green Group)}

This patient was a 67-year-old retired man referred for 20 years of progressively worsening low-back pain, characterized as bandlike across the musculature of the lower back, radiating occasionally to the left gluteal region. He was neurologically intact and underwent unsuccessful nonoperative therapy. Radiographic imaging at initial presentation demonstrated dextroscoliosis with a coronal Cobb angle of $16^{\circ}$. His CSVL, SVA, PT, PI, and LL measured $1 \mathrm{~cm}, 2 \mathrm{~cm}, 24^{\circ}, 74^{\circ}$, and $60^{\circ}$, respectively, which placed him in the "green" group. Additional radiographic findings included extensive degenerative disease, disc bulges, and central canal and foraminal stenosis at multiple levels. Preoperative VAS and ODI scores were 67 and 28, respectively. He was subsequently treated with L1-5 extreme lateral interbody fusion (Nuvasive, Inc.), and L1-5 percutaneous pedicle screws ("green" surgery). The patient had an uneventful postoperative course. At the most recent follow-up evaluation the patient's coronal Cobb angle, CSVL, SVA, PT, PI, and LL measured $10^{\circ}, 1 \mathrm{~cm}, 0 \mathrm{~cm}, 25^{\circ}, 74^{\circ}$, and $61^{\circ}$, respectively, while the VAS and ODI scores were 0 and 11.1 points, respectively (Fig. 2).

\section{Case 12 (Yellow Group)}

This patient was a 58-year-old retired woman with a long history of low-back pain, bilateral gluteal pain, and paresthesias radiating to the lower extremities. The patient did not experience loss of bowel or bladder control, and nonoperative therapies were unsuccessful. Preoperative imaging demonstrated dextroscoliosis with a coronal Cobb angle of $23^{\circ}$, and CSVL, SVA, PT, PI, and LL measurements of $2 \mathrm{~cm}, 8 \mathrm{~cm}, 15^{\circ}, 67^{\circ}$, and $51^{\circ}$, respectively, which placed her in the "yellow" group. Her preoperative VAS and ODI scores were 100 and 84, respectively. She was subsequently treated with L2-5 lateral interbody fusions, L2-3 and L3-4 ALL release, L5-S1 ALIF, with L2-iliac instrumentation ("yellow" surgery). Her postoperative course was complicated by a surgical site infection that was secondarily reopened and debrided, treated with antibiotics, and subsequently healed well. She experienced marked symptom resolution, with a postoperative coronal Cobb angle of $14^{\circ}$, and CSVL, SVA, PT, PI, and LL measurements of $1 \mathrm{~cm}, 0 \mathrm{~cm}, 14^{\circ}, 67^{\circ}$, and $56^{\circ}$, respectively. Her postoperative VAS and ODI scores were 60 and 42, respectively (Fig. 3).

\section{Case 24 (Red Undertreated Group)}

This patient was a 67-year-old man with chronic back pain with intermittent radiating symptoms in his right leg. Walking and standing aggravated the symptoms. He had tried nonoperative therapies without success. He denied any weakness or urinary incontinence. Preoperative parameters were a coronal Cobb angle of $54^{\circ}$, CSVL $2 \mathrm{~cm}$, SVA $12 \mathrm{~cm}, \mathrm{PT} 40^{\circ}$, PI $71^{\circ}$, and LL $35^{\circ}$, which placed him in the "red" group. His dual x-ray absorptiometry scan was within normal limits. He subsequently underwent lateral interbody fusions from T-12 to L-5 and an ALIF at L5-S1. He had 2 levels of ALL release at L2-3 and L3-4. This was followed by Stage II surgery, including posterior percutaneous pedicle screw fixation from T-10 to the sacrum ("yellow" surgery). Postoperative imaging demonstrated a coronal Cobb angle of $29^{\circ}$, CSVL $6 \mathrm{~cm}$, SVA $5 \mathrm{~cm}$, PT $26^{\circ}$, PI $71^{\circ}$, and LL $74^{\circ}$. His postoperative course was uneventful, and at the most recent follow-up evaluation his VAS score had improved from 76 to 53 and his ODI score had improved from 50 to 30 (Fig. 4).

\section{Discussion}

Adult degenerative scoliosis encompasses a wide spectrum of spinal deformity associated with a loss of 
Lateral approach for adult degenerative scoliosis

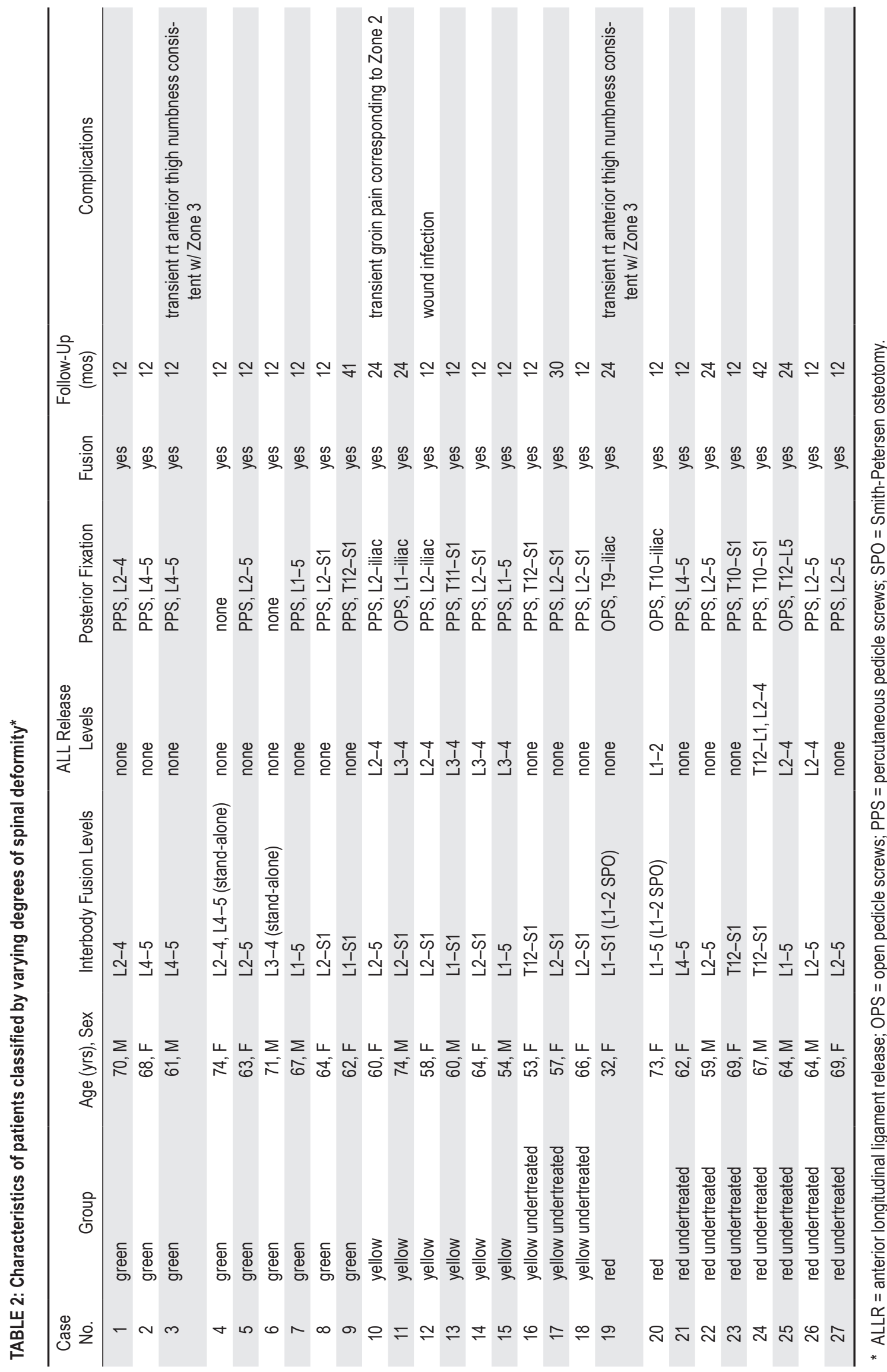




\section{A. R. Deukmedjian et al.}

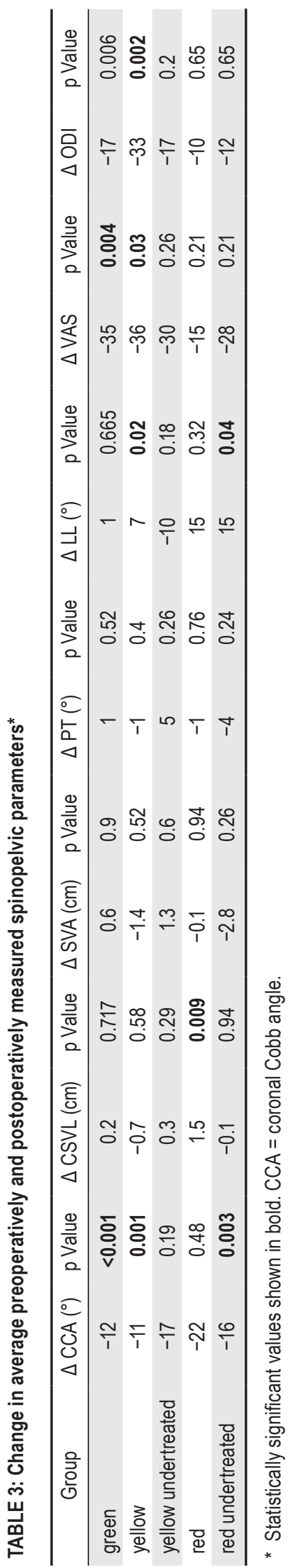

sagittal, coronal, and axial balance. ${ }^{21,28}$ Studies of patients with spinal deformity by Schwab et al. have demonstrated that global spinal malalignment is a strong predictor of disability and that failure to account for pelvic alignment when treating spinal deformity increases the risk for global imbalance, decompensation, and treatment failure. ${ }^{24-27}$ Studies show that health-related quality of life scores following surgery for adult degenerative scoliosis are strongly correlated with the achievement of sagittal balance (SVA $<5 \mathrm{~cm}$ ) and spinopelvic harmony (PT $<$ $25^{\circ}$, PI-LL mismatch $\left.<9^{\circ}\right) .{ }^{3,24-27}$

The surgeon who corrects the deformity must be prepared to offer both minimally invasive as well as traditional open surgical correction in this diverse patient population. Numerous studies have shown that MIS techniques decrease costs, preserve postoperative muscle mass, decrease physiological stress on the patient, and improve perioperative complications such as blood loss, infection, and narcotic use. ${ }^{13,19,23,31,36}$ Specifically, percutaneous pedicle screws, anterolateral approaches, neuromonitoring, specialized instrumentation for deformity correction, improved imaging, and bone morphogenetic protein have been critical in allowing spine surgeons to manage these complex pathologies in a minimally invasive fashion. ${ }^{4,5,9,11,12,14,22,34,35,38}$ However, with MIS treatment of spinal deformity, the ability to provide correction is limited with respect to what traditional open techniques can provide.

With the problems that arise with revision surgery for deformity, including a more challenging procedure and higher complication rates, the importance of performing the correct procedure initially is magnified. $7,8,15,17,18,20,29$ The surgeons capable of performing open and MIS techniques for deformity should then ask themselves: "What is the least amount of surgery for this particular patient that will improve symptoms, improve sagittal balance, and achieve spinopelvic harmony?"4 For the lateral access surgeon, the question may be: "In which patient population will a stand-alone lateral interbody fusion at the coronal apex suffice? Or will this patient need more sagittal correction, requiring an ALL release and lateral interbody cage placement, providing anterior column support and delivering graft for fusion, combined with posterior osteotomies." Although there is a growing literature base concerning the lateral treatment of adult spinal deformity, there remains a paucity of data on when and how it should be implemented. ${ }^{4,5,9,11,12}$ The authors seek a radiographic roadmap with respect to the lateral approach for treating spinal deformity.

In addition to obtaining a thorough history and performing a physical examination, the key factors used in our study to separate patients into categories were coronal Cobb angle, PI-LL mismatch, SVA, PT, comorbidities, and curve flexibility. Patients were assigned to a color category based on the worst radiographic skeletal criteria. For example, if a patient's SVA was $<5 \mathrm{~cm}$ but the PI-LL mismatch was $20^{\circ}-30^{\circ}$, they were classified into the yellow, or worse, group. This system explains certain anomalies in our data, such as the average PT in the yellow group that was $18^{\circ}$ preoperatively.

Patients with a mild coronal imbalance (coronal Cobb 
Lateral approach for adult degenerative scoliosis

TABLE 4: Comparison of average preoperatively and postoperatively measured spinopelvic parameters

\begin{tabular}{|c|c|c|c|c|c|c|c|c|}
\hline Group & $\operatorname{CCA}\left({ }^{\circ}\right)$ & CSVL (cm) & SVA $(\mathrm{cm})$ & $\mathrm{PT}\left({ }^{\circ}\right)$ & $\mathrm{PI}\left({ }^{\circ}\right)$ & $\operatorname{LL}\left({ }^{\circ}\right)$ & VAS & ODI \\
\hline \multicolumn{9}{|l|}{ green } \\
\hline preop & 23 & 2 & 2 & 18 & 58 & 55 & 74 & 47 \\
\hline postop & 11 & 2 & 2 & 19 & 58 & 56 & 39 & 30 \\
\hline \multicolumn{9}{|l|}{ yellow } \\
\hline preop & 22 & 2 & 5 & 18 & 56 & 37 & 89 & 64 \\
\hline postop & 11 & 1 & 4 & 17 & 58 & 44 & 53 & 31 \\
\hline \multicolumn{9}{|c|}{ yellow undertreated } \\
\hline preop & 32 & 1 & 0 & 26 & 72 & 55 & 82 & 63 \\
\hline postop & 15 & 2 & 1 & 31 & 71 & 45 & 52 & 46 \\
\hline \multicolumn{9}{|l|}{ red } \\
\hline preop & 44 & 1 & 6 & 36 & 71 & 32 & 85 & 70 \\
\hline postop & 22 & 2 & 6 & 35 & 72 & 47 & 70 & 60 \\
\hline \multicolumn{9}{|c|}{ red undertreated } \\
\hline preop & 29 & 4 & 7 & 32 & 68 & 39 & 60 & 44 \\
\hline postop & 13 & 4 & 4 & 29 & 68 & 54 & 41 & 32 \\
\hline
\end{tabular}

angle $<30^{\circ}$ ), who are sagittally neutral (SVA $<5 \mathrm{~cm}$ ), with a flexible curve, comorbidities, a PT $<20^{\circ}$, and a minimal PI-LL mismatch of $<20^{\circ}$ may be candidates for stand-alone lateral interbody fusion (green group). This is a good option for those fragile patients without other surgical options, limited by age (> 80 years old) or multiple severe comorbidities. The impact on sagittal balance is minimal, but surgery may limit curve progression as well as provide indirect decompression at the same time. Also in the green group are the patients who are similar except for a PT of $20^{\circ}-25^{\circ}$ but who remain sagittally neutral (SVA $<5 \mathrm{~cm}$ ) and without significant comorbidities. For that patient, the role of the lateral approach may be for multiple interbody fusions limited to the apex of a small coronal curve. Taken together, the patients in the green group had a coronal Cobb angle improvement of $12^{\circ}$, from $23^{\circ}$ to $11^{\circ}$, which was statistically significant $(\mathrm{p}<$ 0.001 ). As could be expected in this group with minimal deformity, the changes in SVA, PT, and LL were small and not statistically significant. However, there was a
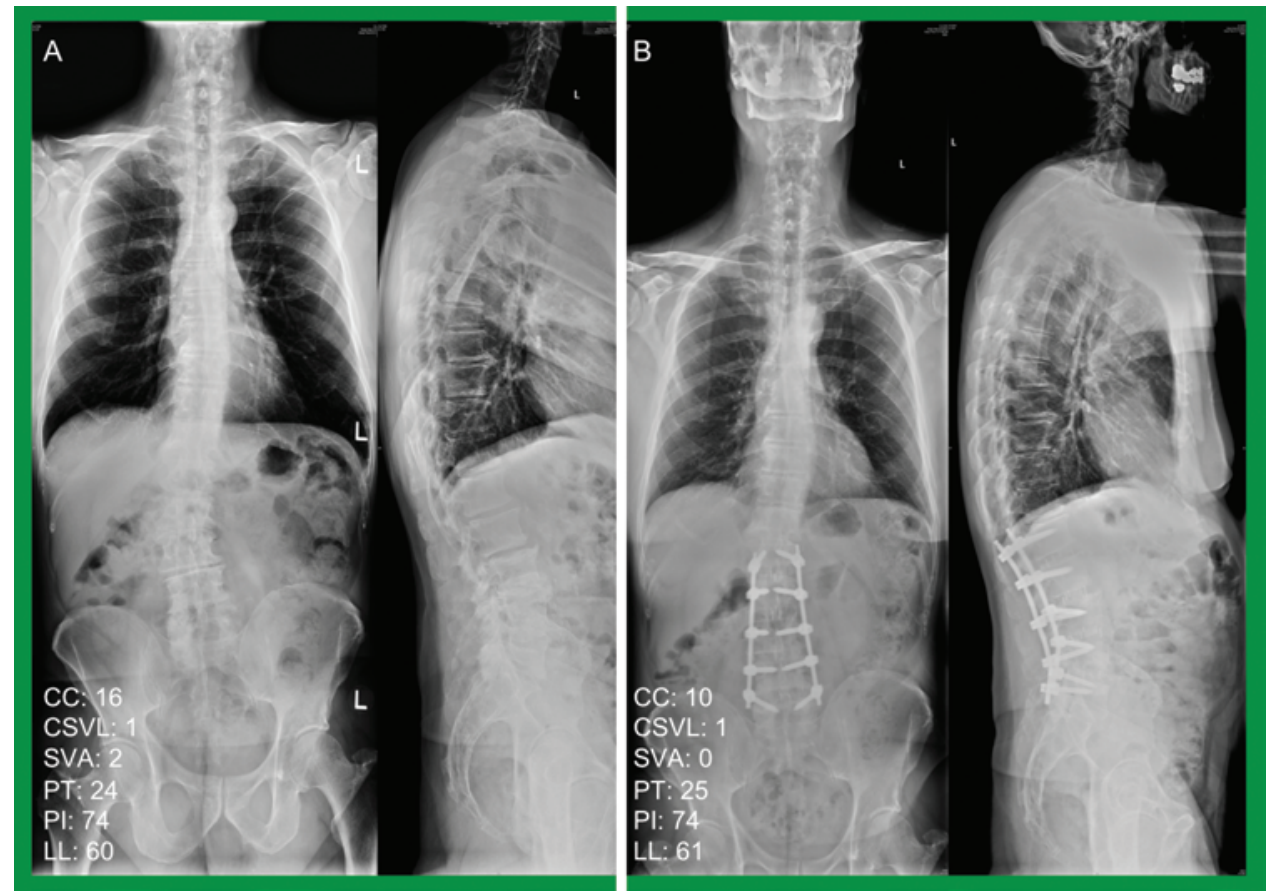

FIG. 2. Case 7. Anteroposterior and lateral 36 -inch radiographs of a patient with mild deformity (green group). A: Preoperative images of a patient with mild compensated deformity. B: Postoperative images obtained after L1-5 MIS-lateral interbody fusion and percutaneous posterior fixation showing restoration of disc height, improvement in coronal Cobb angle, and no significant change in other spinopelvic parameters. 


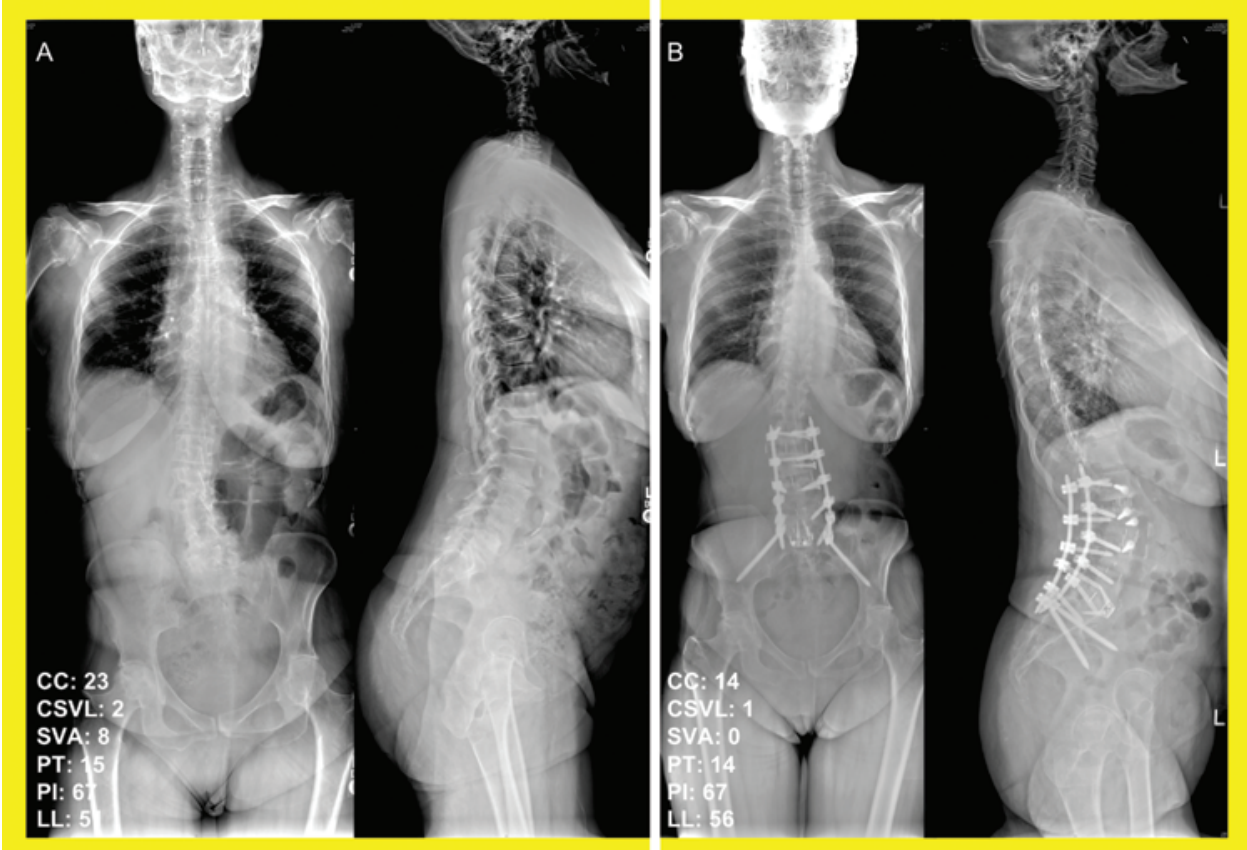

FIG. 3. Case 12. Anteroposterior and lateral 36 -inch radiographs of a patient with moderate deformity (yellow group). A: Preoperative images of a patient with moderate deformity. B: Postoperative images obtained after L2 -5 MIS-lateral interbody fusion with ALL release and posterior fixation from L-2 to the ilium, showing restoration of disc height and improvement in spinopelvic parameters.

statistically significant reduction in the VAS of 35 points $(\mathrm{p}=0.004)$, while the ODI approached statistical significance with a 17 -point reduction $(\mathrm{p}=0.006)$. Interestingly, in the green group the SVA increased by an average of $0.6 \mathrm{~cm}(\mathrm{p}=0.717)$, likely resulting from not attempting to increase sagittal balance in this patient population; however, this increase apparently had minimal impact on clinical outcomes. Making efforts to increase the lumbar lordosis and overcorrecting sagittal balance in these patients would likely have required a larger surgery, may not necessarily have improved outcome measures, and increased the risk of complications (Tables 3 and 4).

The yellow group included 9 patients with moderate adult degenerative scoliosis, with a coronal Cobb angle $>30^{\circ}$, a PI-LL mismatch of $20^{\circ}-30^{\circ}$, with compensated $\left(\mathrm{PT} 25^{\circ}-30^{\circ}\right.$ ) positive sagittal balance (SVA 5-9 cm), a
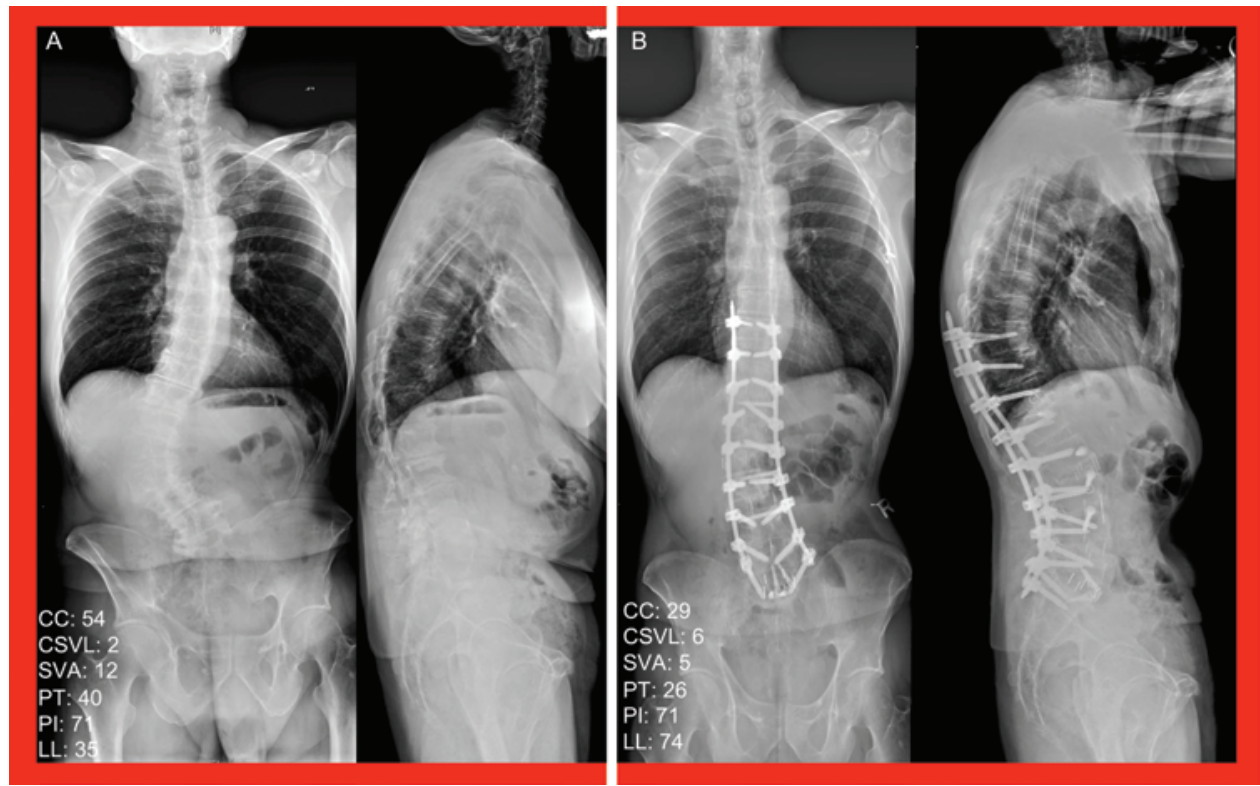

FIG. 4. Case 24. Anteroposterior and lateral 36-inch radiographs of a patient with severe deformity (red group). A: Preoperative images of a patient with severe deformity. B: Postoperative images obtained after T10-S1 open posterior arthrodesis with osteotomies and with MIS-lateral interbody fusion with multilevel ALL release, showing restoration of disc height and improvement in spinopelvic parameters. 
flexible curve, and no significant medical comorbidities. Six of the 9 patients classified into this subgroup underwent surgery consistent with our roadmap. Statistically significant measurements in this group were a coronal Cobb angle decrease of $11^{\circ}$, from $22^{\circ}$ to $11^{\circ}$ (p $\left.<0.001\right)$, LL increase from $37^{\circ}$ to $44^{\circ}(\mathrm{p}=0.02)$, and improvements in VAS and ODI scores of $36(\mathrm{p}=0.03)$ and $33(\mathrm{p}=0.002)$ points, respectively. The average changes in CSVL, SVA, and PT were small and not statistically significant. On average, the PI-LL mismatch decreased from $29^{\circ}$ to $14^{\circ}$ for this group. Overall, the most significant aspect of the yellow group was not a change in radiographic parameter, but rather the statistically significant improvement in patient outcome scores.

Three of the 9 patients in the "yellow" category had less extensive surgery ("green") than suggested in our roadmap (the yellow undertreated group). No parameters in this subgroup had values of statistical significance, likely resulting from the small number of patients. Although the coronal Cobb angle decreased by $17^{\circ}$, the SVA, PT, and LL all increased, worsening spinopelvic parameters. This worsening was likely due to surgical undercorrection, and was understood by our surgical team as a learning point.

The red group was composed of 9 patients, and included those with severe sagittal imbalance whose compensatory mechanisms were maximized $\left(\mathrm{PT}>30^{\circ}\right.$, PI-LL $>30^{\circ}$, and thoracic hypokyphosis, although not included in this study). The surgery we recommend for these sagittally decompensated patients, although in the past have not always provided, includes the previously discussed lateral MIS techniques with either Ponte osteotomies if the SVA is less than $14 \mathrm{~cm}$, or a pedicle subtraction osteotomy if the SVA is greater than $14 \mathrm{~cm}$. To maximize sagittal improvement in these patients, an L5-S1 ALIF should almost always be performed. Two of the 9 patients classified into this subgroup underwent surgery consistent with our roadmap; however, due to the small number of patients in this cohort, all measurements were statistically insignificant, except for the change in CSVL, which increased by $1.5 \mathrm{~cm}$ $(\mathrm{p}=0.009)$. Although the VAS and ODI scores improved by 15 and 10 points, respectively, they were not statistically significant. Despite the small cohort, treating the "red" group with "red" surgery improved most radiographic values, including coronal Cobb angle (decreased by $22^{\circ}$ ), PT (decreased by $1^{\circ}$ ), and LL (increased by $15^{\circ}$ ).

Seven of the 9 patients in the "red" category received less surgery ("green" or "yellow") than suggested in our roadmap (red undertreated group). Statistically significant values in this group included a decrease in coronal Cobb angle of $16^{\circ}(\mathrm{p}=0.003)$, and an increase in LL of $15^{\circ}(\mathrm{p}=0.04)$. All other values improved, including CSVL (decrease by $0.1 \mathrm{~cm}$ ), SVA (decrease by $2.8 \mathrm{~cm}$ ), PT (decrease by $4^{\circ}$ ), and VAS and ODI scores (decrease by 28 and 12 points, respectively).

The prior 5 years of incorporating the lateral approach to our surgical armamentarium have been a learning experience. As demonstrated in the current study, many of our patients with positive sagittal alignment have been undercorrected using the lateral approach. Future innovations will likely allow significant improvement in sagittal balance and thus improvements in clinical outcome and reduction in reoperation rates.

This study should not be taken as an algorithm on how to treat adult degenerative scoliosis from a minimally invasive approach. Rather, it is a description of our experience and lessons learned in treating a difficult group of patients, especially with our previous report of inadequate sagittal correction in one-third of a cohort undergoing lateral MIS for adult degenerative scoliosis. ${ }^{9}$ Through preoperative and postoperative radiographic measures and patient-reported outcomes analysis, the authors discuss a suitable approach to help guide surgical treatment, including decompression, instrumented posterior spinal fusion, anterior spinal fusion, and osteotomy, with a focus on the lateral approach. The clinical gains of minimally invasive techniques, when applied to these cases, may be even greater by diminishing exposure-related morbidity. While the surgical literature remains limited to preliminary experiences and early short-term results, our experience and an expansion of our knowledge with these advanced techniques is progressing swiftly.

\section{Future Challenges}

A major challenge with lateral MIS techniques is that they are powerful when correcting coronal imbalance, but when used without additional anterior or posterior releases they will likely have a minimal impact on lumbar lordosis and subsequently on sagittal balance, as demonstrated in our study. The potential for a poor outcome if basic spinopelvic parameters are not maintained has been discussed, and should be in the thoughts of any surgeon performing lateral MIS for adult degenerative scoliosis.

For these techniques to become the standard of care, a number of impediments to individual adoption must be acknowledged and overcome. First, one of the primary barriers to the application of this technology is related to the steep learning curve associated with these techniques. Second, MIS techniques require a strong understanding of 3D spinal anatomy. At our institution, surgeons undergo multiple anatomical, biomechanical, and cadaveric training sessions to refine skills and avoid the complications of these techniques. ${ }^{10,12,33}$ Finally, unforeseen health care changes have the potential to diminish funding for new product development. Modern instrumentation has been developed for longer-segment fixation, fusion, and segmental manipulation, making MIS for deformities a feasible option in select patients. We learned after 5 years of using the lateral approach that it is versatile and may play a significant role in adult degenerative scoliosis when used correctly and for the correct indication.

\section{Study Limitations}

In addition to the complexity of spinopelvic parameters, the growing number of surgical procedures, both in the minimally invasive and traditional realms, makes any classification scheme from a lateral MIS perspective difficult. However, we believe that some basic principles, as outlined in this study, may be used as a roadmap when approaching adult degenerative scoliosis from a lateral approach. 


\section{A. R. Deukmedjian et al.}

Radiographic outcomes in this series are likely to be inferior in terms of deformity correction when compared with an open surgical series. As an evolving discipline, minimally invasive deformity surgery currently lags behind traditional techniques such as open osteotomy, mainly due to technological limitations. While this is currently an area of active research, it remains a tradeoff when trying to achieve lower complication rates than those associated with open surgery. In addition, the lack of dorsal bone exposure for a fusion surface will likely result in higher rates of pseudarthrosis at segments where an interbody fusion is not performed.

The emerging importance of 36-inch standing radiographs has altered the treatment paradigms of spine surgery. At our institution, only in the last 24 months have these radiographs been consistently maintained on all patients. In addition, although attempts are made to have every patient return outcome measures to us, we are not always successful, which causes a limitation in the available number of patients for the current study. However, the relatively few publications on this topic have inadequate outcome measurements and are lacking in 36-inch standing radiographs. For this reason, our cohort $(n=27)$ is one of the largest in the literature with regards to lateral MIS for adult degenerative scoliosis correction..$^{4,9,32}$

\section{Conclusions}

The potential of the lateral approach in the treatment of adult degenerative scoliosis has yet to be realized. It is a versatile option for almost all types of adult deformity surgery, and will continue to evolve in this rapidly changing field of MIS. This study is an early attempt to determine when and how it can be used. For the patient with uncompensated and minimal sagittal and coronal imbalance (green subgroup), our outcomes show that a stand-alone or limited segmental lateral interbody fusion with posterior fixation at the curve apex should be adequate. For the yellow subgroup (moderate deformity), correction of sagittal imbalance can be achieved through some combination of lateral ALL release with or without MIS facetectomy with posterior fixation. For more severe deformity (red subgroup, sagittally unbalanced with rigid deformity curves), a hybrid MIS-open procedure will likely be needed. However, the lateral approach may be used in these cases for either an ALL release with hyperlordotic cage placement or interbody fusions for anterior column support and arthrodesis.

\section{Disclosure}

Dr. Uribe is a paid consultant and receives research grants from NuVasive, LLC.

Author contributions to the study and manuscript preparation include the following. Conception and design: Deukmedjian, Ahmadian, Bach, Uribe. Acquisition of data: Ahmadian, Uribe. Analysis and interpretation of data: Deukmedjian, Ahmadian, Bach, Uribe. Drafting the article: all authors. Critically revising the article: Deukmedjian, Ahmadian, Uribe. Reviewed submitted version of manuscript: Deukmedjian, Uribe. Approved the final version of the manuscript on behalf of all authors: Deukmedjian. Statistical analysis: Ahmadian, Bach, Uribe. Administrative/technical/material support: Deukmedjian, Uribe. Study supervision: Uribe.

\section{Acknowledgments}

The authors would like to thank Donald Smith, M.D., and Jotham Manwaring, M.D., for their invaluable contributions to the production of this manuscript.

\section{References}

1. Aebi M: The adult scoliosis. Eur Spine J 14:925-948, 2005

2. Ahmadian A, Deukmedjian AR, Abel N, Dakwar E, Uribe JS: Analysis of lumbar plexopathies and nerve injury after lateral retroperitoneal transpsoas approach: diagnostic standardization. A review. J Neurosurg Spine 18:289-297, 2013

3. Ames CP, Smith JS, Scheer JK, Bess S, Bederman SS, Deviren $\mathrm{V}$, et al: Impact of spinopelvic alignment on decision making in deformity surgery in adults. A review. J Neurosurg Spine 16:547-564, 2012

4. Anand N, Baron EM, Thaiyananthan G, Khalsa K, Goldstein TB: Minimally invasive multilevel percutaneous correction and fusion for adult lumbar degenerative scoliosis: a technique and feasibility study. J Spinal Disord Tech 21:459-467, 2008

5. Benglis DM, Elhammady MS, Levi AD, Vanni S: Minimally invasive anterolateral approaches for the treatment of back pain and adult degenerative deformity. Neurosurgery 63 (3 Suppl):191-196, 2008

6. Birknes JK, White AP, Albert TJ, Shaffrey CI, Harrop JS: Adult degenerative scoliosis: a review. Neurosurgery 63 (3 Suppl):94-103, 2008

7. Cho KJ, Bridwell KH, Lenke LG, Berra A, Baldus C: Comparison of Smith-Petersen versus pedicle subtraction osteotomy for the correction of fixed sagittal imbalance. Spine (Phila Pa 1976) 30:2030-2038, 2005

8. Cho SK, Bridwell KH, Lenke LG, Yi JS, Pahys JM, Zebala LP, et al: Major complications in revision adult deformity surgery: risk factors and clinical outcomes with 2- to 7-year follow-up. Spine (Phila Pa 1976) 37:489-500, 2012

9. Dakwar E, Cardona RF, Smith DA, Uribe JS: Early outcomes and safety of the minimally invasive, lateral retroperitoneal transpsoas approach for adult degenerative scoliosis. Neurosurg Focus 28(3):E8, 2010

10. Dakwar E, Vale FL, Uribe JS: Trajectory of the main sensory and motor branches of the lumbar plexus outside the psoas muscle related to the lateral retroperitoneal transpsoas approach. Laboratory investigation. J Neurosurg Spine 14:290-295, 2011

11. Deukmedjian AR, Dakwar E, Ahmadian A, Smith DA, Uribe JS: Early outcomes of minimally invasive anterior longitudinal ligament release for correction of sagittal imbalance in patients with adult spinal deformity. ScientificWorldJournal 2012:789698, 2012

12. Deukmedjian AR, Le TV, Baaj AA, Dakwar E, Smith DA, Uribe JS: Anterior longitudinal ligament release using the minimally invasive lateral retroperitoneal transpsoas approach: a cadaveric feasibility study and report of 4 clinical cases. Laboratory investigation. J Neurosurg Spine 17:530539, 2012

13. Dickerman RD, East JW, Winters K, Tackett J, Hajovsky-Pietla A: Anterior and posterior lumbar interbody fusion with percutaneous pedicle screws: comparison to muscle damage and minimally invasive techniques. Spine (Phila Pa 1976) 34:E923-E925, 2009

14. Eck JC, Hodges S, Humphreys SC: Minimally invasive lumbar spinal fusion. J Am Acad Orthop Surg 15:321-329, 2007

15. Eichholz KM, Ryken TC: Complications of revision spinal surgery. Neurosurg Focus 15(3):E1, 2003

16. Fessler RG, O'Toole JE, Eichholz KM, Perez-Cruet MJ: The development of minimally invasive spine surgery. Neurosurg Clin N Am 17:401-409, 2006

17. Glassman SD, Hamill CL, Bridwell KH, Schwab FJ, Dimar JR, Lowe TG: The impact of perioperative complications on 
clinical outcome in adult deformity surgery. Spine (Phila Pa 1976) 32:2764-2770, 2007

18. Lapp MA, Bridwell KH, Lenke LG, Daniel Riew K, Linville DA, Eck KR, et al: Long-term complications in adult spinal deformity patients having combined surgery a comparison of primary to revision patients. Spine (Phila Pa 1976) 26:973983, 2001

19. Lee KH, Yue WM, Yeo W, Soeharno H, Tan SB: Clinical and radiological outcomes of open versus minimally invasive transforaminal lumbar interbody fusion. Eur Spine J 21:22652270,2012

20. Linville DA, Bridwell KH, Lenke LG, Vedantam R, Leicht $\mathrm{P}$ : Complications in the adult spinal deformity patient having combined surgery. Does revision increase the risk? Spine (Phila Pa 1976) 24:355-363, 1999

21. Mummaneni PV, Lenke LG, Haid RW Jr: Spinal Deformity: A Guide to Surgical Planning and Management. St. Louis, MO: Quality Medical Publishing, 2008

22. Mummaneni PV, Tu TH, Ziewacz JE, Akinbo OC, Deviren V, Mundis GM: The role of minimally invasive techniques in the treatment of adult spinal deformity. Neurosurg Clin N Am 24: 231-248, 2013

23. Peng CW, Yue WM, Poh SY, Yeo W, Tan SB: Clinical and radiological outcomes of minimally invasive versus open transforaminal lumbar interbody fusion. Spine (Phila Pa 1976) 34: 1385-1389, 2009

24. Schwab F, Lafage V, Patel A, Farcy JP: Sagittal plane considerations and the pelvis in the adult patient. Spine (Phila Pa 1976) 34:1828-1833, 2009

25. Schwab F, Patel A, Ungar B, Farcy JP, Lafage V: Adult spinal deformity-postoperative standing imbalance: how much can you tolerate? An overview of key parameters in assessing alignment and planning corrective surgery. Spine (Phila Pa 1976) 35:2224-2231, 2010

26. Schwab F, Ungar B, Blondel B, Buchowski J, Coe J, Deinlein D, et al: Scoliosis Research Society-Schwab adult spinal deformity classification: a validation study. Spine (Phila Pa 1976) 37:1077-1082, 2012

27. Schwab FJ, Blondel B, Bess S, Hostin R, Shaffrey CI, Smith JS, et al: Radiographic spino-pelvic parameters and disability in the setting of adult spinal deformity: a prospective multicenter analysis. Spine (Phila Pa 1976) [epub ahead of print], 2013

28. Silva FE, Lenke LG: Adult degenerative scoliosis: evaluation and management. Neurosurg Focus 28(3):E1, 2010

29. Simmons ED: Surgical treatment of patients with lumbar spinal stenosis with associated scoliosis. Clin Orthop Relat Res (384):45-53, 2001

30. Smith JS, Shaffrey CI, Kuntz C IV, Mummaneni PV: Classifi- cation systems for adolescent and adult scoliosis. Neurosurgery 63 (3 Suppl): 16-24, 2008

31. Smith WD, Christian G, Serrano S, Malone KT: A comparison of perioperative charges and outcome between open and miniopen approaches for anterior lumbar discectomy and fusion. J Clin Neurosci 19:673-680, 2012

32. Tormenti MJ, Maserati MB, Bonfield CM, Okonkwo DO, Kanter AS: Complications and radiographic correction in adult scoliosis following combined transpsoas extreme lateral interbody fusion and posterior pedicle screw instrumentation. Neurosurg Focus 28(3):E7, 2010

33. Uribe JS, Arredondo N, Dakwar E, Vale FL: Defining the safe working zones using the minimally invasive lateral retroperitoneal transpsoas approach: an anatomical study. Laboratory investigation. J Neurosurg Spine 13:260-266, 2010

34. Uribe JS, Smith DA, Dakwar E, Baaj AA, Mundis GM, Turner $\mathrm{AW}$, et al: Lordosis restoration after anterior longitudinal ligament release and placement of lateral hyperlordotic interbody cages during the minimally invasive lateral transpsoas approach: a radiographic study in cadavers. Laboratory investigation. J Neurosurg Spine 17:476-485, 2012

35. Wang MY: Percutaneous iliac screws for minimally invasive spinal deformity surgery. Minim Invasive Surg 2012:173685, 2012

36. Wang MY, Lerner J, Lesko J, McGirt MJ: Acute hospital costs after minimally invasive versus open lumbar interbody fusion: data from a US national database with 6106 patients. J Spinal Disord Tech 25:324-328, 2012

37. Wang MY, Ludwig SC, Anderson DG, Mummaneni PV: Percutaneous iliac screw placement: description of a new minimally invasive technique. Neurosurg Focus 25(2):E17, 2008

38. Wang MY, Madhavan K: Mini-open pedicle subtraction osteotomy: surgical technique. World Neurosurg [epub ahead of print], 2012

39. Wang MY, Williams S, Mummaneni PV, Sherman JD: Minimally invasive percutaneous iliac screws: initial 24 case experience with CT confirmation. J Spinal Disord Tech [epub ahead of print], 2012

Manuscript submitted April 15, 2013.

Accepted May 28, 2013.

Please include this information when citing this paper: DOI: 10.3171/2013.5.FOCUS13173

Address correspondence to: Armen Deukmedjian, M.D., Department of Neurosurgery and Brain Repair, University of South Florida, 2 Tampa General Circle, 7th Floor, Tampa, FL 33606. email: armen deuk@gmail.com. 